\title{
Gaussian Kernel
}

National Cancer Institute

\section{Source}

National Cancer Institute. Gaussian Kernel. NCI Thesaurus. Code C79422.

A kernel function described by the equation: $\left((2 \mathrm{PI})^{\wedge}(-0.5)\right)^{*} \exp \left(-\mathrm{u}^{\wedge}(2) / 2\right)$ with $\mathrm{u}=(\mathrm{x}-\mathrm{xi}) / \mathrm{h}$, where $\mathrm{h}$ is the window width and $\mathrm{xi}$ are the values of the independent variable in the data, and $\mathrm{x}$ is the value of the independent variable for which one seeks an estimate. 